\title{
Macroscopia do aparelho digestório do cágado sul- americano Mesoclemmys vanderhaegei (Bour, 1973)
}

\section{Macroscopic aspects of the Gastrointestinal Tract of the South American freshwater turtle Mesoclemmys vanderhaegei (Bour, 1973)}

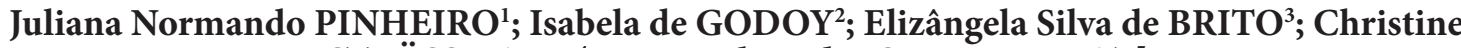 \\ STRÜSSMANN $^{4}$; Rosa Helena dos Santos FERRAZ
}

\author{
${ }^{1}$ Discente do Programa de Pós-graduação em Ciências Veterinárias da Faculdade de Agronomia e Medicina Veterinária da \\ Universidade Federal de Mato Grosso, Cuiabá-MT \\ ${ }^{2}$ Discente do Curso de Medicina Veterinária da Faculdade de Agronomia e Medicina Veterinária da Universidade Federal de \\ Mato Grosso, Cuiabá-MT \\ ${ }^{3}$ Bióloga autônoma, Programa de Pós-graduação em Ecologia e Conservação da Biodiversidade do Instituto de Biociências da \\ Universidade Federal de Mato Grosso, Cuiabá-MT \\ ${ }^{4}$ Docente do Programa de Pós-graduação em Ecologia e Conservação da Biodiversidade do Instituto de Biociências da \\ Universidade Federal de Mato Grosso, Cuiabá-MT \\ ${ }^{5}$ Docente do Programa de Pós-graduação em Ciências Veterinárias da Faculdade de Agronomia e Medicina Veterinária da \\ Universidade Federal de Mato Grosso, Cuiabá-MT
}

\begin{abstract}
Resumo
Ainda há poucas descrições anatômicas a cerca do trato digestório de representantes da ordem Testudines, especialmente sobre o cágado-de-Vanderhaegei, Mesoclemmys vanderhaegei. A ocorrência desta espécie abrange as bacias dos rios Paraguai, Paraná e Amazônica. Estudos sobre a sua ecologia e morfologia ainda são pouco explorados, dessa forma, o aparelho digestório foi caracterizado macroscopicamente pela dissecção desse sistema em dez espécimes. A boca possui comprimento orocaudal ligeiramente maior que o laterolateral. Os lábios são formados por placas córneas. A língua é macia e está totalmente fixada ao assoalho da cavidade oral. O esôfago possui luz ampla e paredes delgadas na região cervical, tornando-se gradativamente mais estreito e de paredes espessas caudalmente. O estômago apresenta forma semelhante à letra "U" e podem ser distinguidas as regiões do cárdia, do corpo e do piloro, com mucosa totalmente pregueada. Na transição deste para o intestino delgado o esfíncter pilórico é conspícuo. O intestino apresenta-se disposto entre o delgado e grosso, sendo o primeiro constituído pelo duodeno e jejuno, não sendo possível identificar macroscopicamente o íleo. Da mesma forma, não se observa o ceco como primeiro segmento do intestino grosso, sendo este formado pelo cólon, que se abre em um pequeno compartimento pigmentado da cloaca. O fígado apresenta variação no padrão de lobação, no entanto, a presença dos lobos hepáticos direito e esquerdo é constante nos espécimes analisados. O pâncreas é facilmente observado em sintopia com o duodeno. Nesta análise, o trato digestório de Mesoclemmys vanderhaegei apresenta padrão semelhante ao de outras espécies de quelônios pesquisados da família Chelidae.
\end{abstract}

Palavras-chave: Cágado. Morfologia. Aparelho digestório. Quelônio.

\begin{abstract}
There are few anatomical descriptions about the testudines's gastrointestinal tract, especially when concerned to the Vanderhaege's turtle, Mesoclemmys vanderhaegei. The geographical range of this species extends throughout the Paraguai, Paraná and Amazon river basins. Studies about its ecology and morphology are still little exploited, thus, the gastrointestinal apparatus was macroscopic characterized through the dissection of ten specimens. The mouth's oralaboral length is wider than its oral-tail length. The lips are formed by keratinized structures. The tongue is soft and fixed to the floor of the oral cavity. The cervical esophagus is broad and has thin walls, becoming narrower and thicker in its caudal portion. The stomach's shape resembles the "U" letter. It has a creased mucosa and is divided in a cardiac, a main body, and a pyloric region. The gut is presented as the small and large intestine. The duodenum and jejunum are easily identified. The ileum, on the opposite, is unidentifiable macroscopically, as well as the caecum, the first segment of the large intestine. The colon, the posterior segment, opens itself into a cloaca. The liver presents individual variation regarding lobation pattern. However, the presence of both liver lobes, left and right, is a constant finding during the observation. The pancreas is easily seen running distally along the duodenum. In this analysis, it was verified that the digestive tract in Mesoclemmys vanderhaegei is similar to the tract of other chelids previously studied.
\end{abstract}

Keywords: Fresh water turtle. Morphology. Gastrointestinal tract. Chelids.

Correspondência para:

Juliana Normando Pinheiro

Av. Minuano n 165 , Res. São Conrado Casa 14

Jd. Bom Clima, Cep:78048-223
Cuiabá- MT

E-mail: jnpvet@yahoo.com.br

Recebido: 27/10/2009

Aprovado: 04/11/2010 


\section{Introdução}

Mesoclemmys vanderhaegei é um cágado sulamericano de água doce, popularmente conhecido como cágado-de-Vanderhaege ou cágado-do-Cerrado. Sua ocorrência é descrita em localidades do norte da Argentina, Paraguai, Sudeste e CentroOeste do Brasil ${ }^{1,2,3}$, nas bacias dos rios Paraguai e Paraná e na periferia da bacia Amazônica. Lagoas de água rasa, com vegetação aquática densa e árvores esparsas nas margens constituem o seu habitat natural ${ }^{1}$. No Cerrado, a presença da espécie foi identificada também em córregos oligotróficos, com ou sem vegetação nativa ${ }^{1,4}$. Seus hábitos e aspectos referentes à sua história natural, assim como de várias outras espécies de quelônios no Brasil, são ainda pouco explorados.

Alguns pesquisadores apontam a ausência de dados sobre a morfologia das espécies de cágados como uma das causas primordiais para os inconsistentes arranjos taxonômicos do grupo ${ }^{5}$, além de dificultar abordagens mais amplas sobre vários aspectos ecológicos e evolutivos das espécies ${ }^{3}$. Por outro lado, o forrageamento em quelônios representa um dos aspectos mais abordados neste grupo ${ }^{3,6,7}$, pelo fato de que a matéria-prima e a energia obtidas através do alimento influenciam seu crescimento, a manutenção e reprodução ${ }^{8}$. Entretanto, apesar da predominância das pesquisas voltadas a esta área, pouco ainda se conhece sobre a morfologia do aparelho digestório desses animais ${ }^{3}$.

Desta forma, o presente estudo tem como objetivo descrever os aspectos macroscópicos dos vários segmentos do aparelho digestório em Mesoclemmys vanderhaegei com vistas à caracterização da espécie e à produção de informações que viabilizem análises comparativas com outros quelônios. Posteriormente ainda, fornecer subsídios para futuros estudos evolutivos do grupo, em especial àqueles voltados às adaptações relacionadas ao hábito alimentar.

\section{Material e Método}

Foram utilizados dez espécimes de Mesoclemmys vanderhaegei, sendo oito fêmeas (quatro exemplares adultos e quatro juvenis) e dois machos (um exemplar adulto e outro juvenil), com pesos variando entre 68 e 680 gramas, capturados em habitats naturais no município de Chapada dos Guimarães, Mato Grosso. Os cágados foram capturados no período de março a julho de 2008, com armadilhas tipo covo (funnel trap), As coletas foram autorizadas pelo IBAMA sob a licença de número $n^{\circ}$ 12089-1 e o procedimento experimental foi submetido e aprovado pelo Comitê de Ética em Pesquisa Animal da Universidade Federal de Mato Grosso sob o protocolo de número 23108026254/08-0.

Os animais foram eutanasiados por sobrecarga anestésica de tiopental (Thiopental ${ }^{\circledR}$ ) por via intra-celomática, na dose de $150 \mathrm{mg} / \mathrm{kg}$. Comprovado o óbito, foi desarticulado e retirado o plastrão, com o auxílio de uma serra circular, para a fixação dos animais por imersão em solução aquosa de formaldeído a $10 \%$. O fígado recebeu injeções da mesma solução fixadora em seu parênquima. Somente após duas semanas nesta solução os animais foram dissecados.

A descrição macroscópica, as relações topográficas e a documentação fotográfica das estruturas constituintes do aparelho digestório dos animais foram realizadas in situ, a fresco e após fixação. Após o término do experimento, os animais coletados serão depositados na Coleção de Vertebrados da Universidade Federal do Mato Grosso. Com vistas à padronização dos termos anatômicos foi adotada a nomenclatura preconizada na Nomina Anatomica Veterinaria9.

\section{Resultados}

O aparelho digestório em Mesoclemmys vanderhaegei é composto de boca, esôfago, estômago intestinos delgado e grosso, cloaca e glândulas anexas, fígado e pâncreas. 
A boca (Figura 1) está delimitada rostralmente pelos lábios córneos, dorsalmente pelo palato duro, lateralmente contínua aos lábios e comissura labial e ventralmente pela mandíbula, pelo osso hioide, língua e músculos associados, formando o assoalho desta cavidade. O limite caudal não é visível macroscopicamente, assim como também não é possível visualizar os limites da faringe. As paredes da boca delimitam uma ampla cavidade oral, cujo comprimento orocaudal é ligeiramente maior que sua largura, com lábios imóveis formados por placas córneas queratinizadas, de margens cortantes e coloração amarela. Tanto o lábio superior quanto o inferior apresentam formato semelhante à letra V. O lábio superior possui, além da lâmina cortante, uma lâmina horizontal, que contribui para a formação do palato duro, enquanto o lábio inferior possui medianamente, em sua superfície cortante, uma projeção pontiaguda. O encontro dos lábios superior e inferior ocorre no angulus oris, constituído por tecido maleável. O palato duro apresenta formato triangular e está revestido por mucosa de aspecto liso e róseo. Nesta região, observam-se as coanas, e caudalmente a elas, em posição dorsolateral, os óstios faríngeos da tuba auditiva, direita e esquerda. As paredes ventrolaterais da cavidade oral são constituídas pelos ramos da mandíbula, pela língua, aparelho hioide, músculos e cartilagens associados.

A língua (Figura 1) de formato triangular, consistência macia, de coloração rósea e brilhante, é fixada em toda a sua extensão ao assoalho da cavidade oral. $\mathrm{O}$ revelo de mucosa que reveste esse órgão apresenta inúmeras estruturas arredondadas distribuídas de modo uniforme. Na raiz, porção mais larga, observase a abertura da laringe em posição mediana.

O esôfago é contínuo caudalmente à cavidade oral. Apresenta-se como uma estrutura tubular, inicial-

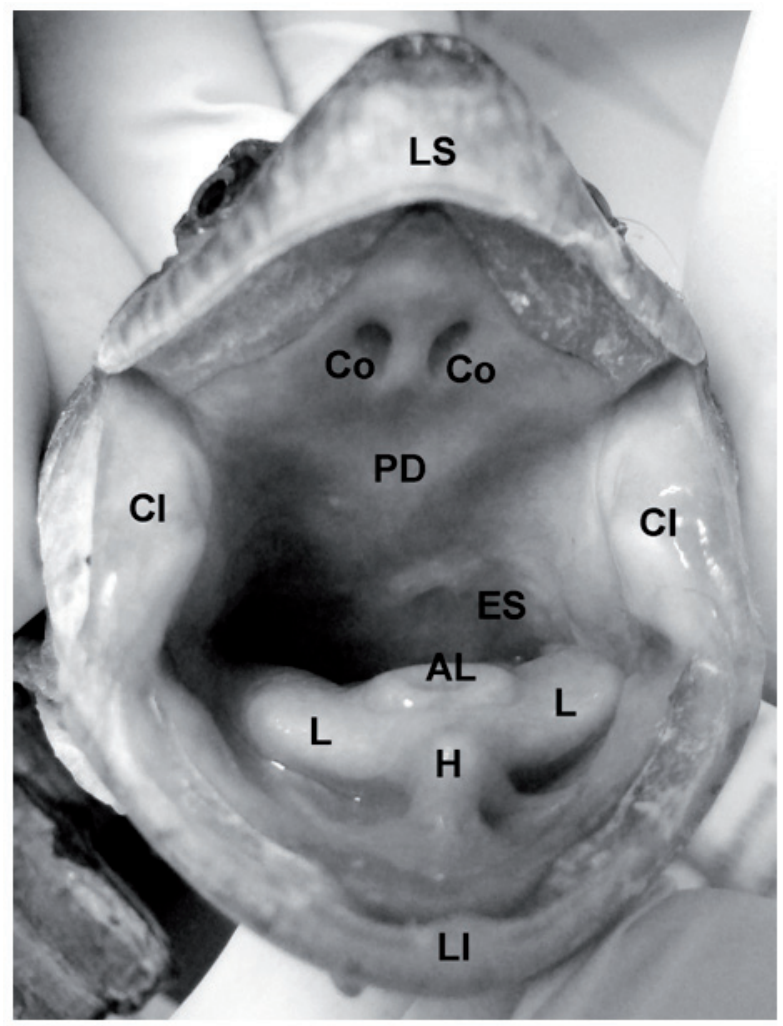

Figura 1 - Cavidade oral de Mesoclemmys vanderhaegei, vista cranial. Lábios superior (LS) e inferior (LI), coanas (Co), palato duro (PD), comissuras labiais (Cl), parte cranial do esôfago cervical (ES), abertura da laringe $(\mathrm{AL})$, língua $(\mathrm{L})$ e osso hioide $(\mathrm{H})$, revestido pela mucosa 
mente localizada dorsalmente à traqueia (segmento cervical), desviando-se levemente para a direita à medida que se direciona caudalmente e por fim, posicionando-se à esquerda da traqueia e dorsalmente ao coração, ao entrar na cavidade celomática, imediatamente antes de desembocar no estômago formando o segmento celomático (Figura 2).

O segmento cervical do esôfago apresenta luz ampla e paredes delgadas de aspecto transparente. Próximo à entrada da cavidade celomática há a redução no diâmetro da luz e aumento da espessura de sua parede, caracterizando o esôfago celomático, cujo arranjo, se mantém até a desembocadura no estômago. A mucosa do segmento cervical é lisa e à medida que se direciona caudalmente, próximo ao estômago, apresenta pregas orientadas longitudinalmente (Figura 3A).
Essas pregas são uniformes e apresentam base larga e ápice delgado.

O estômago, situado à esquerda da cavidade celomática, apresenta-se de forma tubular similar à letra "U" (Figura 2). A coloração de sua superfície externa é esbranquiçada, lisa e brilhante com diâmetro variável, sendo o menor nas regiões de transição com o esôfago (parte cárdica) e com o intestino delgado (parte pilórica), independentemente do grau de repleção gástrica. $\mathrm{O}$ maior diâmetro está limitado à região do corpo gástrico, compreendido entre as partes cárdica e pilórica, esta última é marcada por uma estrutura anelar, de consistência firme, o esfíncter pilórico. O estômago apresenta duas faces, uma parietal e outra visceral, respectivamente, posicionadas dorsal e ventralmente. A curvatura ventricular menor faz sintopia

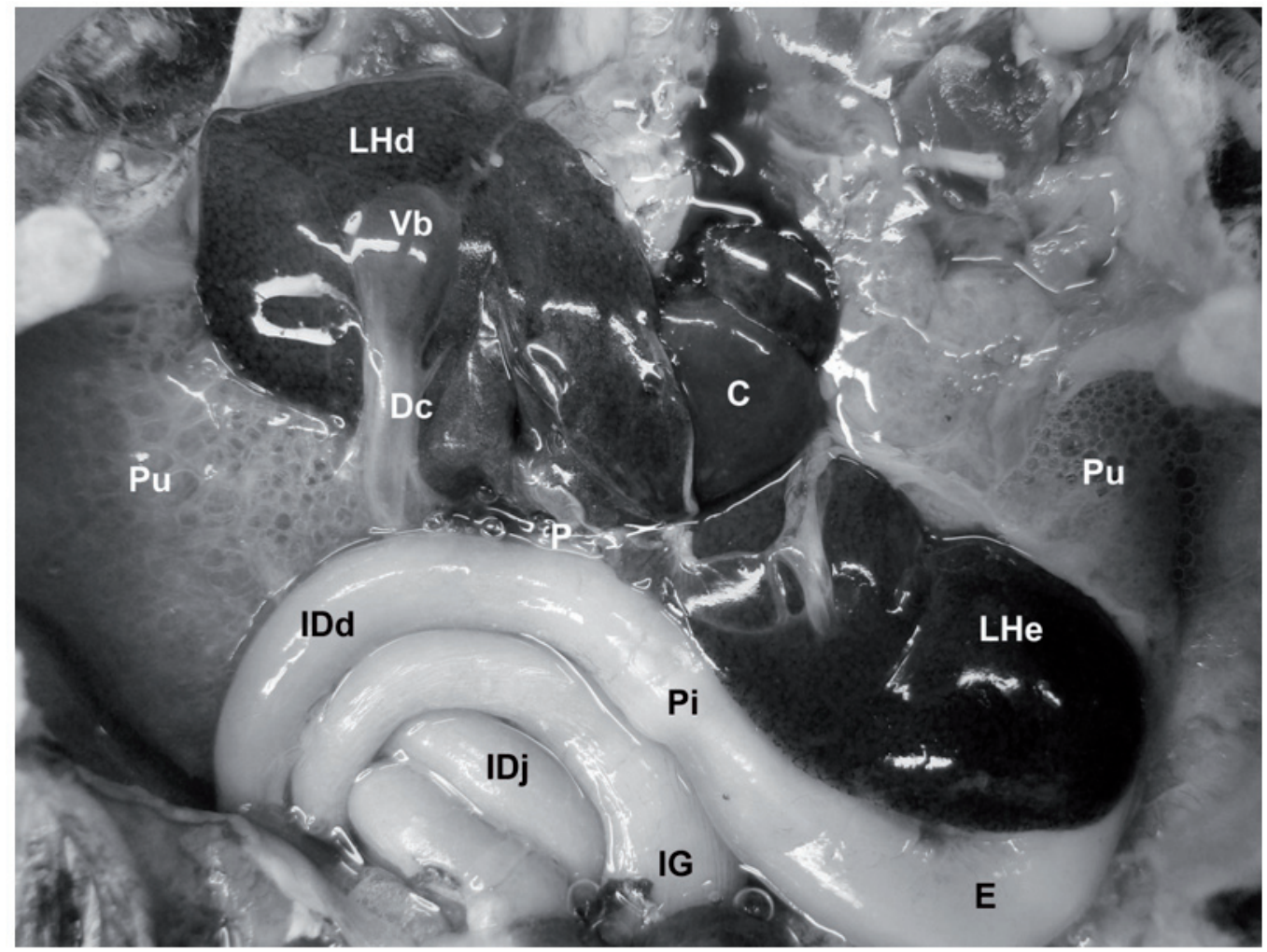

Figura 2 - Vista ventral dos órgãos a fresco de Mesoclemmys vanderhaegei no interior da cavidade celomática. O lobo hepático direito(LHd) do fígado foi refletido cranialmente para permitir a visualização da vesícula biliar $(\mathrm{Vb})$ e ducto colédoco (Dc) desembocando no duodeno(IDd). Lobos hepáticos direito (LHd) e esquerdo (LHe), estômago (E), piloro $(\mathrm{Pi})$, duodeno - parte descendente (IDd), Intestino delgado - jejuno (IDj), intestino grosso $(\mathrm{IG})$, coração $(\mathrm{C})$, pâncreas $(\mathrm{P})$ e pulmão $(\mathrm{Pu})$ 


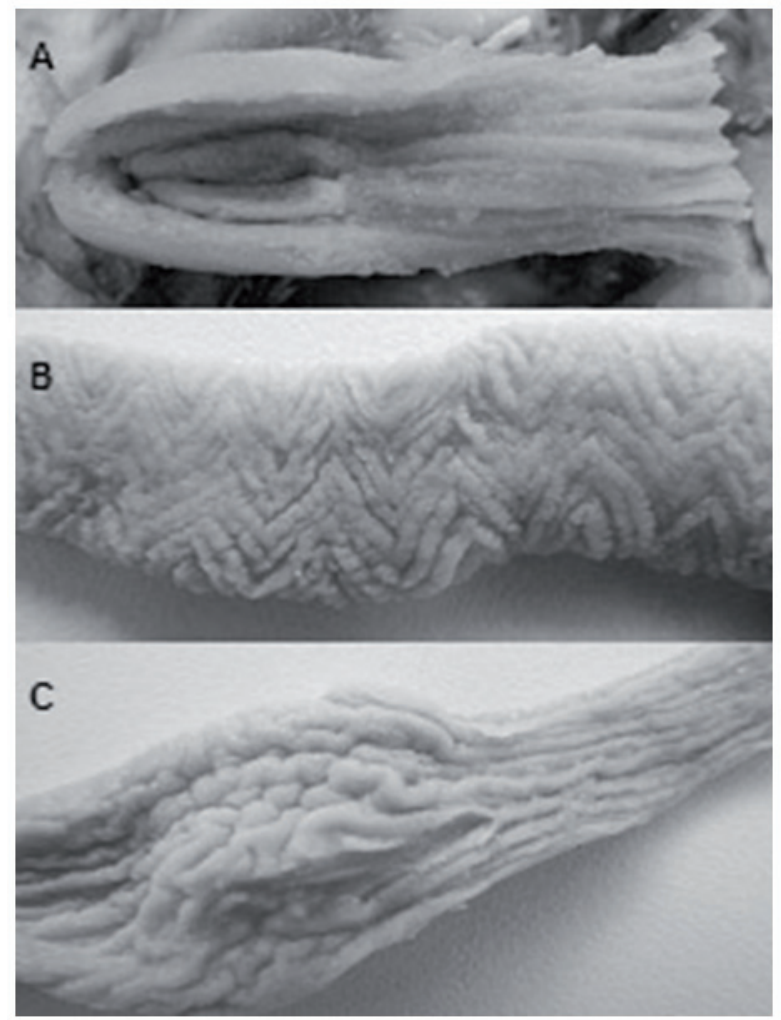

Figura 3 - (A) mucosa na transição do esôfago (à direita) para o estômago (à esquerda), da porção cranial do intestino delgado (B) e da transição (C) do intestino delgado (à direita) para o intestino grosso (à esquerda) em Mesoclemmys vanderhaegei

com o lobo hepático esquerdo através da distribuição desse segmento do fígado parcialmente pelas faces parietal e visceral do estômago, enquanto a curvatura ventricular maior posiciona-se opostamente à menor, próxima à ponte da carapaça. A sintopia do estômago com o lobo hepático esquerdo se faz pelo posicionamento desse segmento do fígado junto à curvatura ventricular menor, distribuindo-se parcialmente pelas faces parietal e visceral do estômago. O baço também faz sintopia com o estômago, localizando-se na face dorsal do mesmo, acompanhando sua curvatura ventricular maior. A mucosa do estômago, bastante pregueada, apresenta-se uniforme em todo o órgão e disposta longitudinalmente ao sentido do trânsito da ingesta (Figura $3 \mathrm{~A}$ ).

Os intestinos delgado e grosso são identificados na inspeção externa pela diferença de seus diâmetros. O intestino delgado corresponde a uma estrutura tu- bular longa e de coloração esbranquiçada (Figura 2). Este segmento apresenta diâmetro uniforme ao longo de toda a sua extensão, diferindo, entre os indivíduos estudados, quanto ao trajeto e o número de circunvoluções do jejuno. A primeira parte do intestino delgado, o duodeno (parte cranial), inicia-se após o piloro, à esquerda da cavidade celomática, cruzando transversalmente em direção à direita, onde realiza a primeira flexura (flexura duodenal cranial) para então seguir caudalmente curvando-se em sentido centrípeto (anti-horário), formando assim a parte descendente do duodeno. Este realiza outra flexura (flexura duodenal caudal) e volta-se em sentido centrífugo, dando origem ao segmento ascendente. A partir deste ponto, o intestino apresenta de quatro a sete circunvoluções, em sentido variado, formando a segunda parte do intestino delgado, o jejuno. Dentre os espécimes analisados, quatro (40\%) apresentam quatro circun- 
voluções, outros quatro (40\%) cinco, em um animal (10\%) seis e em outro (10\%) sete circunvoluções. A região de transição para o intestino grosso ocorre em sintopia com o piloro e a porção inicial do duodeno. Não há evidências, na anatomia externa do intestino delgado, que permitam estabelecer limites entre jejuno e íleo, tampouco identificar este último segmento do intestino delgado, assim como não se observam limites entre o intestino delgado e grosso. Após o jejuno, em sentido caudal, nota-se apenas um aumento gradual do diâmetro. A mucosa do intestino delgado apresenta pregas dispostas em zigue-zague (Figura 3 B) em todos os segmentos, sendo que a amplitude das mesmas reduz-se em direção caudal, tendendo à linearidade na sua porção final (Figura 3 C), na região de transição para o intestino grosso.

O intestino grosso, por sua vez, mostra-se de diâmetro amplo e comprimento curto quando comparado ao intestino delgado (Figura 2). Apresenta uma porção transversa (cólon transverso), localizada medianamente na cavidade celomática, e flexiona-se à esquerda (flexura cólica esquerda). Sua continuação em direção caudal origina a parte descendente do intestino grosso (cólon descendente) a qual desemboca na cloaca. A mucosa dessa região apresenta proeminente pregueamento longitudinal e uniforme (Figura 3 C).

A cloaca apresenta-se como uma estrutura pigmentada e de compartimento único comum aos tratos digestório, urinário e reprodutor. Sua região inicial é determinada pela presença evidente de um estreitamento na parede da porção final do intestino grosso, o reto, além da clara mudança de mucosa, que se torna lisa e posteriormente enegrecida.

O fígado ocupa toda a extensão láterolateral da cavidade celomática, na altura da ponte. É um órgão de consistência firme e coloração castanho-escura (Figura 2). A face dorsal (visceral) mostra depressões que correspondem à impressão deixada pelas vísceras que fazem sintopia com o órgão, enquanto a face ventral (parietal) é arredondada e se apoia na superfície interna do plastrão. O fígado faz sintopia craniodorsalmente aos pulmões, caudalmente ao estômago e intestino delgado e cranialmente ao coração, sendo separado deste por uma fina membrana serosa. A observação externa revela a presença dos lobos hepáticos direito e esquerdo, distribuídos por toda a região central da cavidade celomática. O lobo hepático direito, localizado totalmente à direta do plano mediano, apresenta duas regiões, com base na forma do lobo e na presença de incisura: a primeira, de formato globoso e em contato com a face interna da ponte direita, contém a vesícula biliar; a segunda, de forma achatada e pontiaguda semelhante à ponta de lança, localiza-se medialmente à primeira região. Esta segunda porção do lobo hepático direito apresenta-se ausente em dois dos indivíduos estudados (20\%). O lobo hepático esquerdo também está constituído por duas regiões distintas: a primeira, em formato piramidal, localiza-se caudalmente ao coração; a segunda, alongada, direciona-se obliquamente para a região caudolateral esquerda da cavidade celomática. Em sua extremidade, esta porção divide-se em outras duas porções: uma dorsal e outra ventral que, respectivamente, posicionam-se na face dorsal e ventral da curvatura menor do estômago (curvatura ventricular menor).

A vesícula biliar apresenta formato piriforme e paredes delgadas transparentes, que permitem a verificação da coloração esverdeada da bile nesta espécie. Apresenta três regiões: o fundo, o corpo e o colo, sendo este contínuo ao ducto colédoco. O ducto colédoco (Figura 2) é facilmente visualizado desembocando na margem mesenterial da parte cranial do duodeno. Em todos os casos estudados a vesícula apresenta-se associada à face visceral da parte globosa do lobo hepático direito, e em cinco animais, o fundo da vesícula foi observado simultaneamente na face parietal do fígado.

O pâncreas apresenta-se como um órgão de consistência macia, coloração amarelo-clara, de formato 
alongado, presente em sua maior porção à direita, em sintopia com a parte cranial do duodeno, especificamente na margem antimesenterial, estendendo-se desde o piloro até a altura da desembocadura do ducto colédoco (Figura 2).

\section{Discussão}

As descrições do trato digestório de quelônios apresentadas por diversos autores ${ }^{6,10,11,12}$ são gerais, não particularizando espécie alguma. Neste contexto, corroboram as informações encontradas em Mesoclemmys vanderhaegei quanto à descrição da boca como sendo formada por lábios duros, queratinizados e cortantes, e da cavidade oral, bastante ampla. O formato triangular da língua e a forma de fixação da mesma ao assoalho da cavidade oral são semelhantes ao descrito por Ashley ${ }^{10}$ para quelônios em geral e por Wyneken ${ }^{12}$, para as tartarugas marinhas. A abertura da laringe na região dorsomediana da raiz da língua também é descrita para tartarugas marinhas ${ }^{12}$. A presença de papilas linguais, entretanto, tal como descrito por Ashley ${ }^{10}$, não foi identificada macroscopicamente em $M$. vanderhaegei.

A presença da faringe é citada por outros autores ${ }^{10,12}$ de forma pouco detalhada. Assim como ressaltado no presente trabalho, não se observam particularidades macroscópicas na transição entre a cavidade oral e o esôfago que possam claramente caracterizá-la como uma região específica. Considerando que estruturas como a laringe e os óstios faríngeos da tuba auditiva pertencem à faringe em espécies de outras classes superiores, e que no cágado-de-Vanderhaege estas estruturas estão deslocadas cranialmente, sugerimos para essa região a designação de cavidade orofaríngea, como ocorre em peixes.

O esôfago inicia-se posteriormente à cavidade oral e apresenta formato e localização semelhante às descrições gerais realizadas para indivíduos da família Chelidae $^{10,12}$. Outros autores ${ }^{13}$, estudando o esôfago da tartaruga-da-Amazônia (Podocnemis expansa), descrevem que o mesmo apresenta a mucosa pregueada, aspecto este consistente com nossos achados na porção do esôfago presente na região celomática. Outros trabalhos pesquisados ${ }^{6,10,11,12,13}$ não mencionam a diferença de diâmetro e de espessura da parede deste órgão entre o que poderíamos chamar de esôfago cervical em relação ao celomático. Esta diferença é bastante evidente no nosso estudo, sendo a parte cervical de grande diâmetro e de paredes finas, em contraposição ao esôfago celomático, de diâmetro menor e paredes espessas.

Pressler et al. ${ }^{14}$, em estudo endoscópico com tartarugas marinhas e em uma tartaruga gigante da Malásia, relataram que a mucosa esofágica mostra-se recoberta por papilas, pontiagudas e arredondadas, direcionadas ao estômago, as quais poderiam dificultar o trânsito retrógrado de alimento ou de corpos estranhos. A presença destas papilas também é corroborada por outro estudo com tartarugas marinhas ${ }^{12}$, e também em estudos com espécimes da família Pelomedusidae ${ }^{13,15}$ (Peltocephatus dumerilianus, Podocnemis expansa, P. unifilis e P. sextuberculata). Vogt, Sever e Moreira $^{13}$, entretanto, relatam a ausência das papilas em espécies estudadas da família Chelidae (Phrynops raniceps, P. geoffroanus, Platemys platycephala e Chelus fimbriatus). Este estudo confirma as nossas observações para Mesoclemmys vanderhaegei, e que poderia ser justificado por estudos referentes ao tipo de alimento ingerido e às condições durante o forrageamento, embora as espécies supracitadas sejam todas de ambientes aquáticos.

O estômago do M. vanderhaegei apresenta tamanho e forma semelhantes às descrições gerais para outras espécies de quelônios ${ }^{10,11,12,15,16,17}$. Boyer e Boyer ${ }^{11} \mathrm{e}$ Bello et al. ${ }^{16}$, em estudo radiográfico contrastado do trato gastrointestinal em tartarugas marinhas, descrevem a presença de um esfíncter particularmente estreito na região de transição do esôfago para o estômago, não sendo este visualizado em nosso estudo. 
Nos estudos com a tartaruga-da-Amazônia ${ }^{15,18}$, o estômago é descrito com forma achatada e encurvada, com a região pilórica bem desenvolvida, correspondendo também aos nossos achados. A presença do piloro também é ressaltada por Wyneken ${ }^{12}$, nas tartarugas marinhas. As regiões do cárdia e do corpo gástrico não são citadas pelos outros autores supracitados.

Os achados referentes ao intestino delgado em $M$. vanderhaegei assemelham-se aos de outras espécies de quelônios ${ }^{6,10,11,12,15}$. Boyer e Boyer ${ }^{11}$ descrevem o intestino delgado deste grupo como sendo relativamente curto e menos enrolado quando comparado com o de mamíferos. Embora esta informação seja, aparentemente, condizente com nossos achados, acreditamos ser possível confirmá-la, somente, após estudos morfométricos. Outros autores ${ }^{12,16}$, estudando animais marinhos, questionam essa informação, descrevendo intestinos relativamente longos e adaptados aos hábitos alimentares herbívoros dessas espécies, baseados no consumo de plantas aquáticas. A tartaruga-daAmazônia, um cágado herbívoro, também apresenta o intestino delgado longo, com base em uma descrição morfológica do trato digestório ${ }^{15}$ e em um estudo de determinação do tempo do trânsito gastrointestinal ${ }^{18}$. A descrição sobre os hábitos alimentares do $M$. vanderhaegei por Brito ${ }^{4}$ expõe esta espécie como sendo onívora, com predileção por itens alimentares de origem animal, o que justificaria os achados supracitados quanto ao tamanho e circunvoluções, considerando que o término da digestão das proteínas ocorre no intestino delgado ${ }^{19}$.

A diferenciação do intestino delgado em duodeno, jejuno e íleo também é descrita como de difícil identificação macroscópica em quelônios marinhos ${ }^{12}$. $\mathrm{Na}$ observação da anatomia externa dessa víscera, os parâmetros que permitem a diferenciação entre o duodeno e o jejuno são a localização e a presença de circunvolução, no entanto, o íleo, se presente, não pode ser macroscopicamente identificado. Em tartarugas marinhas, a mucosa do intestino delgado foi descrita por Wyneken ${ }^{12}$ como sendo semelhante a uma colmeia de abelhas, fato este díspar do observado neste estudo, onde o pregueamento da mucosa apresenta disposição em zigue-zague.

O intestino grosso em M. vanderhaegei apresentase similar às descrições disponíveis dessa víscera em quelônios ${ }^{6,10,11,12,15}$. Apresenta comprimento menor e diâmetro maior que o intestino delgado, conforme descrito genericamente para as tartarugas marinhas ${ }^{12}$ e na tartaruga-da-Amazônia ${ }^{15,18}$. O ceco, descrito por Boyer e Boyer ${ }^{11}$ como sendo pouco desenvolvido nos quelônios, não é observado em Mesoclemmys vanderhaegei. Em contrapartida, Lopes ${ }^{18}$ discorre sobre a aparente importância deste segmento no tempo de trânsito gastrointestinal, em Podocnemis expansa, um cágado herbívoro, após estudo radiográfico contrastado do trato digestório dessa espécie.

O fígado em $M$. vanderhaegei apresenta tamanho, coloração e topografia semelhantes aos de outras espécies de quelônios ${ }^{6,10,11,12,17,20}$. A lobação deste órgão é pouco descrita ou apontada na literatura, que menciona, em sua grande parte, somente a presença dos lobos hepáticos direito e esquerdo. Em um estudo com muçuãs (Kinosternon scorpioides) ${ }^{20}$ os animais apresentaram cinco lobos, sendo dois à esquerda do plano mediano, que corrobora com os achados deste estudo, e três à direita, o que difere dos aspectos de lobação encontrado no M. vanderhaegei onde o lobo hepático direito apresenta também apenas uma fissura dividindo-o em apenas duas regiões. Para a denominação adequada destas projeções são necessários estudos mais aprofundados concernentes à lobação hepática por meio de angiotécnicas aplicadas aos sistemas circulatório e de drenagem da bile. A vesícula biliar em M. vanderhaegei localiza-se na região dorsal do lobo hepático direito, descrição esta confirmada por Ashley ${ }^{10}$ e Machado ${ }^{20}$, mas contraposta por Wyneken $^{12}$, que descreve a vesícula na superfície ventral do mesmo em quelônios marinhos. Entretanto, em $50 \%$ dos animais analisados é possível visualizar tam- 
bém uma pequena porção da vesícula biliar na região ventral do lobo hepático direito.

A descrição do pâncreas para a espécie em estudo corrobora os achados de outros pesquisadores, com exceção da coloração do mesmo, descrita como róseo-alaranjada por alguns autores ${ }^{11,12}$, enquanto todos os animais estudados apresentam o pâncreas com coloração amarelo-claro. Boyer e Boyer ${ }^{11}$ ainda descrevem a possível localização do pâncreas em contato direto com o baço em quelônios, o que não é observado em M. vanderhaegei.

\section{Conclusões}

Frente aos resultados expostos relativos à anatomia do trato digestório do Mesoclemmys vanderhaegei concluímos que: a boca é ampla, os lábios modificados são formados por placas queratinizadas de margens cortantes e a língua fixada ao assoalho da cavi-

\section{Referências}

1.BRANDÃO, R. A.; SEBBEN, A.; MOLINA, F. B. Notes on distribution and habitats of Acanthochelys spixii and Phrynops vanderhaegei (Testudines, Chelidae) in Central Brazil. Boletin de la Asociación Herpetológica Española, v. 13, p. 11-15, 2002.

2.IVERSON, J. B.; COLLEGE, E. A revised checklist with distribution maps of the turtles of the world. Richmond: J. P. Iverson Publishing, 1992. 363 p.

3.SOUZA, F. L. M.; MARTINS, M.; SAWAYA, R. J. A new record and observations of Vanderhaege's toad-headed turtle, Phrynops vanderhaegei (Testudines, Chelidae) in Brazil. Boletin de la Asociación Herpetológica Española, v. 11, n. 2, p. $85-87,2000$.

4.BRITO, E. S. Hábitos alimentares de Mesoclemmys vanderhaegei (Bour, 1973) (Testudines: Chelidae) em uma estação chuvosa, Região de Chapada Dos Guimarães, Mato Grosso. 2008. 55 f. Tese (Mestrado) - Faculdade de Ciências Biológicas, Fundação Universidade Federal de Mato Grosso, Cuiabá, 2008.

5.BOUR, R.; ZAHER, H. A new species of Mesoclemmys, from the open formations of Northeastern Brazil (Chelonii, Chelidae). Papéis avulsos de Zoologia, São Paulo, v. 45, n. 24 p. 295-311, 2005 .

6. GOULART, C. E. S. Alimentação, forrageamento e dieta. In: Herpetologia, herpetocultura e medicina de répteis Rio de Janeiro: L. F. Livros de Veterinária, 2004. p. 150-156.

7.SOUZA, F. L. Uma revisão sobre padrões de atividade, reprodução e alimentação de cágados brasileiros (Testudineos, Chelidae). Phyllomedusa, v. 3, n. 1, p. 15-27, 2004. dade oral; a faringe não apresenta limites macroscopicamente visíveis; o Mesoclemmys vanderhaegei possui um esôfago cervical com luz ampla e parede delgada, com redução do diâmetro da luz caudalmente, espessamento de parede aumentada nos segmento celomático, com mucosa pregueada; o estômago apresenta as regiões do cárdia, segmento inicial de desembocadura do esôfago; corpo gástrico, correspondente à curvatura do mesmo; e o segmento final pilórico, com esfíncter na transição com o duodeno; o intestino delgado é formado pelos segmentos do duodeno e jejuno, não sendo macroscopicamente evidente o íleo; o intestino grosso é formado pelo cólon, que se abre em um compartimento pigmentado da cloaca, sendo o ceco não visualizado e o fígado e pâncreas apresentam forma e topografia semelhantes à de outros quelônios.

Desta forma, o trato digestório do Mesoclemmys vanderhaegei apresenta padrão semelhante ao de outras espécies de quelônios da família Chelidae.

8. RANDALL, D.; BURGGREN, K.; FRENCH, K. Fisiologia animal: mecanismos e adaptações. Rio de Janeiro: Guanabara Koogan, 2000. 729 p.

9. INTERNATIONAL COMMITEE ON VETERINARY GROSS ANATOMICAL NOMENCLATURA. Nomina Anatomica Veterinaria. Editorial Committee Hannover, 2005. Disponível em: <http://www.wava-amav.org/Downloads/nav_2005.pdf>. Acesso em: 30 mar. 2009.

10. ASHLEY, L. M. Laboratory anatomy of the turtle. Iowa: W C, Brown, 1969. 48 p.

11.BOYER, T. H.; BOYER, D. M. Turtles, tortoise and terrapins. In: MADER, D. R. Reptile medicine and surgery. Philadelphia: W.B. Saunders, 1996. cap. 7, p. 61-78.

12. WYNEKEN, J. The anatomy of sea turtles. Miami: U. S Department of Commerce, 2001. Disponível em: <http:// courses.science.fau.edu/ jwyneken/sta/SeaTurtleAnatomy. pdf $>$. Acesso em: 10 jul. 2009.

13.VOGT, R. C.; SEVER, D. M.; MOREIRA, G. Esophageal papillae in pelomedusid turtles. Journal of Herpetology, v. 32, n. 2, p. 279-282, 1998.

14.PRESSLER, B. M.; GOODMAN, R. A.; HARMS, C. A.; HAWKINS, E. C.; LEWBART, C. A. Endoscopic evaluation of the esophagus and stomach in three loggerhead sea turtles (Caretta caretta) and a Malaysian giant turtle (Orlitia borneensis). Journal of Zoo and Wildlife Medicine, v. 34, n. 1, p. 88-92, 2003.

15.MOREIRA, G. R. S.; LOUREIRO, J. S. Contribucion al estudio de la morfologia del tracto digestivo de individuos jóvenes de Podocnemis expansa (Testudinata: Pelomedusidae). Acta 
Zoologica Lilloana, v. 41, p. 345-348, 1992.

16.BELLO, A.; VALASTRO, C.; STAFFIERI, F.; CROVACE, A. Contrast radiography of the gastrointestinal tract in sea turtles. Veterinary Radiology \& Ultrasound, v. 47, n. 4, p. 351-4. 2006.

17. MALVASIO, A. Aspectos do mecanismo alimentar e da biologia reprodutiva em Podocnemis expansa (Schweigger, 1812), Podocnemisunifilis (Troschel, 1848) e P. sextuberculata (Cornalia, 1849) (Testudines, Pelomedusidae). 2001. 199 f. Tese (Doutorado) - Instituto de Biociências da Universidade de São Paulo, São Paulo, 2001.
18.LOPES, L. A. R. Determinação do tempo do trânsito gastrointestinal em Podocnemis expansa SCWEIGGER, 1812 (Tartaruga-da-Amazônia). 2006. 42 f. Tese (Mestrado) - Faculdade de Medicina Veterinária, Universidade Federal de Uberlândia, Uberlândia, 2006.

19.POUGH, F. H.; JANIS, C. M.; HEISER, J. B. A vida dos vertebrados. 4. ed. São Paulo: Atheneu, 2008. 750 p.

20.MACHADO JÚNIOR, A. A. N.; SOUSA, A. L.; CARVALHO, M. A. M.; SANTOS, F. C. F.; ALVES, F. R. Anatomia do fígado e vias bilíferas do mucuã (Kinosternon scorpioides). Archives of Veterinary Science, v. 10, n. 2, p. 125-133, 2005. 